\title{
Communication
}

Masashi Shimohira*, Keiichi Nagai, Kengo Ohta, Yusuke Sawada, Taku Naiki, Takashi Nagai, Takahiro Yasui, Yuta Shibamoto

\section{Use of microspheres in embolization for unruptured renal angiomyolipomas}

https://doi.org/10.1515/med-2021-0280

received November 4, 2020; accepted March 31, 2021

\begin{abstract}
Purpose - To describe our initial experience with use of microspheres in transcatheter arterial embolization (TAE) for unruptured sporadic renal angiomyolipomas (AMLs). Materials and methods - Seven consecutive patients with seven unruptured sporadic renal AMLs, 6 females and 1 male, with a median age of 45 years (range, 3069 years), underwent TAE using microspheres between November 2016 and February 2020. We evaluated the technical success rate, complications related to the procedure, clinical success rate, and the shrinkage rate of renal AML. Technical success was defined as the completion of TAE. Clinical success was defined as presence of shrinkage of the renal AML after TAE.

Results - In all patients, TAE using microspheres was accomplished and technical success rate was 100\% (7/7). Three patients exhibited slight pain, but it improved with only observation, and the minor complication rate was $43 \%(3 / 7)$ and major complication rate was $0 \%(0 / 7)$. After the TAE, shrinkage of renal AML was confirmed in 6 of 7 patients, and clinical success rate was $86 \%(6 / 7)$. The median of shrinkage rate was $47 \%$ (range, 26-83\%) with a median follow-up period of 19 months (range, 4-30 months).
\end{abstract}

Conclusion - TAE using microspheres appears to be effective and safe for unruptured sporadic renal AMLs.

\footnotetext{
* Corresponding author: Masashi Shimohira, Department of Radiology, Nagoya City University Graduate School of Medical Sciences, Nagoya 467-8601, Japan, e-mail: mshimohira@gmail.com, tel: +81-52-853-8276, fax: +81-52-852-5244

Keiichi Nagai, Kengo Ohta, Yusuke Sawada, Yuta Shibamoto:

Department of Radiology, Nagoya City University Graduate School of Medical Sciences, Nagoya 467-8601, Japan

Taku Naiki, Takashi Nagai, Takahiro Yasui: Department of Nephrourology, Nagoya City University Graduate School of Medical

Sciences, Nagoya, Japan

ORCID: Masashi Shimohira 0000-0003-4907-9111
}

Keywords: renal angiomyolipoma, microspheres, embolization

\section{Introduction}

Renal angiomyolipomas (AMLs) are benign tumors composed of differing degrees of fat, smooth muscle, and abnormal blood vessels and have a propensity to bleed $[1,2]$. Transcatheter arterial embolization (TAE) is an important treatment for renal AMLs [3,4]. Ethanol has been widely used as embolic material in TAE $[5,6]$. However, disadvantages of ethanol embolization include difficulty to control placement, rapid dilution by vascular inflow, and severe pain [7]. Polyvinyl alcohol (PVA) particles were also widely used to embolize renal AMLs [8-10], but they aggregate easily due to their irregular shape and size variability [11]. Vessels might be occluded more proximally than intended, and it can even cause a microcatheter obstruction. On the other hand, microspheres have recently become available in our country. They are precisely calibrated by size, and smoother and more spherical in shape, without fragmentation, than PVA particles [7]. This prevents particle aggregation, thereby allowing the microspheres to better penetrate into smaller vessels than PVA particles of the same size. In this report, we describe our initial experience with the use of microspheres in TAE for unruptured sporadic renal AML.

\section{Materials and methods}

This retrospective study was approved by the Institutional Review Board of Nagoya City University Graduate School of Medical Sciences (approval number 60-19-0205). Written informed consent for the procedure had been obtained from each patient. Seven consecutive patients with seven unruptured sporadic renal AMLs, 6 females and 1 male, with a median age of 45 years (range, 30-69 years), 
underwent TAE using microspheres between November 2016 and February 2020. The indicative criteria for TAE were $4 \mathrm{~cm}$ or larger, or had $5 \mathrm{~mm}$ or larger aneurysmal formation [3].

We reviewed medical records and images and evaluated the technical success rate, complications related to the procedure, clinical success, and the shrinkage rate of renal AMLs. Technical success was defined as the completion of TAE. Complications that required extended hospitalization, required an advanced level of care, or resulted in permanent adverse sequelae or death were classified as major complications, and the remaining complications were considered minor [12]. When focal renal infarction was found, the infarction rate was categorized into: $<10 \%, 10-20 \%$, and $>30 \%$ using angiography immediately after TAE and follow-up computed tomography (CT) according to previously reported criteria [13]. Clinical success was defined as the presence of shrinkage of the renal AML after TAE. Areas of AML were calculated with the following formula [14] from axial CT images on slices showing the maximum AML diameter: (long-axis length $\times$ short-axis length) $\times(\pi / 4)$. The shrinkage rate of AML was calculated with the following formula: \{(initial area - follow-up area)/initial area $\times 100$ (Figure 1a and e). These images were interpreted by two radiologists with more than 13 years of experience in diagnostic and interventional radiology. Any discrepancies were resolved by consensus.

\subsection{Technique of TAE using microspheres for renal AML}

All procedures were approached via the common femoral artery. A 4-Fr sheath was introduced, followed by a 4-Fr catheter. The 4-Fr catheter was advanced to the renal artery, and angiography was performed to confirm the feeding artery and the stain of the renal AML (Figure 1b). A microcatheter was then advanced into the feeding artery of the renal AML as close as possible. Microspheres (Embosphere; Nippon Kayaku, Tokyo, Japan) were suspended in contrast media diluted with normal saline and then injected until the stain of renal AML disappeared (Figure 1c and d). When there were multiple feeding arteries, they were embolized in the same manner. Other embolic materials were not used. In all patients, an intravenous drip infusion of $15 \mathrm{mg}$ pentazocine in $100 \mathrm{~mL}$ saline was administered for pain control during TAE, and the same regimen was added when pain occurred after TAE.

\section{Results}

Results of the TAE using microspheres for renal AMLs are summarized in Table 1. All patients did not have any symptom. The median size of the AML was $54 \mathrm{~mm}$ (range, 40-102 mm), and there was no aneurysmal formation. In all patients, TAE using microspheres was accomplished and thus technical success rate was 100\% (7/7). Microspheres of $100-300 \mu \mathrm{m}$ were used in all patients. Three patients exhibited slight pain, but it improved with only observation. In no patient, extended hospitalization or an advanced level of care was necessary, and no permanent adverse sequelae or death occurred. Thus, the minor complication rate was $43 \%$ (3/7) and major complication rate was $0 \%(0 / 7)$. There was focal renal infarction in 3 of 7 patients (43\%), but infarction rate was less than $10 \%$ in all patients. It was confirmed that there was no renal dysfunction by blood examination. After the TAE,


Figure 1: A 56-year-old woman with left unruptured sporadic renal AML. (a) Contrast-enhanced CT showed AML in the left kidney (circle). The size of the AML was $56 \times 48 \mathrm{~mm}$. (b) Enhancement of the AML (circle) was confirmed by angiography. (c) A microcatheter was advanced into the feeding artery of the AML (arrow). Thereafter, TAE was performed through the microcatheter using 100-300 $\mu \mathrm{m}$ microspheres. (d) Disappearance of enhancement of the tumor was confirmed. The renal infarction rate was $<10 \%$. Slight pain occurred, but it improved with observation. (e) Contrast-enhanced CT 30 months after TAE showed shrinkage of the AML and the size was $44 \times 33 \mathrm{~mm}$ (circle). The shrinkage rate was $46 \%$. 
Table 1: Results of the TAE using microspheres for renal AMLs

\begin{tabular}{|c|c|c|c|c|c|c|c|c|c|c|c|}
\hline Case no. & Age & Sex & Location & $\begin{array}{l}\text { Size } \\
(\mathrm{mm})\end{array}$ & $\begin{array}{l}\text { Technical } \\
\text { success }\end{array}$ & Complication & $\begin{array}{l}\text { Renal } \\
\text { infarction }\end{array}$ & $\begin{array}{l}\text { Follow-up } \\
\text { period } \\
\text { (Mo) }\end{array}$ & $\begin{array}{l}\text { Shrinkage } \\
\text { rate (\%) }\end{array}$ & $\begin{array}{l}\text { Clinical } \\
\text { success }\end{array}$ & Re-TAE \\
\hline 1 & 56 & $\mathrm{~F}$ & $\mathrm{~L}$ & 56 & Yes & Flank pain & $<10 \%$ & 30 & 46 & Yes & No \\
\hline 2 & 32 & $\mathrm{~F}$ & $\mathrm{~L}$ & 40 & Yes & No & No & 26 & 72 & Yes & No \\
\hline 3 & 45 & $\mathrm{~F}$ & $\mathrm{~L}$ & 86 & Yes & No & No & 24 & 26 & Yes & No \\
\hline 4 & 45 & M & $\mathrm{R}$ & 51 & Yes & Flank pain & $<10 \%$ & 14 & 48 & Yes & No \\
\hline 5 & 39 & $\mathrm{~F}$ & $\mathrm{~L}$ & 40 & Yes & Flank pain & $<10 \%$ & 12 & 83 & Yes & No \\
\hline 6 & 69 & $\mathrm{~F}$ & $\mathrm{R}$ & 102 & Yes & No & No & 4 & 36 & Yes & No \\
\hline 7 & 30 & $\mathrm{~F}$ & $\mathrm{~L}$ & 54 & Yes & No & No & 7 & 0 & No & Yes \\
\hline
\end{tabular}

TAE; transcatheter arterial embolization, AML; angiomyolipoma, L; left kidney, R; right kidney.

shrinkage of renal AML was confirmed in 6 of 7 patients, and thus clinical success rate was $86 \%(6 / 7)$. The median of shrinkage rate was $47 \%$ (range, $26-83 \%$ ) with a median follow-up period of 19 months (range, 4-30 months). In one patient $(14 \%)$, the shrinkage of renal AML was not obtained at the follow-up CT 7 months after the TAE, and repeat TAE was performed with ethanol and then the AML was shrunk.

\section{Discussion}

In this study, we demonstrated a high technical success rate $(100 \%)$ and a clinical success rate $(86 \%)$ with low complication rates (minor 43\%, major 0\%). They were acceptable in comparison with those of literature $[5,10$, $15,16]$.

Ethanol is common embolic material to embolize renal AMLs. It denatures blood proteins, clumps damaged erythrocytes, dehydrates vascular endothelial cells, and denudes the vascular wall of all endothelial cells [17]. The advantage of ethanol is that it causes permanent occlusion at a capillary level, thereby inducing tissue necrosis, making it a strong embolic agent. However, there is an associated risk of reflux and nontarget embolization inducing renal infarction. It was recently reported that use of micro-balloon catheter can prevent reflux of ethanol and strengthen the effects of ethanol by preventing dilution from the blood flow and contribute to decreasing the amount of ethanol [18]. Meanwhile, the limitation of the micro-balloon catheter is its high cost, at approximately US $\$ 1,000$.

In this study, focal renal infarction was found in $43 \%$, but they were less than $10 \%$, and no patients had renal dysfunction. Microspheres are compressible and have little tendency to clump together and they can pass through a microcatheter easily and reach the distal vessels corresponding to the particle size. It can contribute to targeted embolization with minimum damage of the normal tissue [11]. Besides, for patients with alcohol hypersensitivity, it can be an important alternative option. In literature, size of used PVA particles for renal AMLs was variously reported to be $47-90 \mu \mathrm{m}$ to $500-710 \mu \mathrm{m}[8,10,15]$. In the present study, we showed use of $100-300 \mu \mathrm{m}$ size of microspheres with good results, and small size particle may contribute to deep penetration of microspheres into the tumor vasculatures.

One patient of this study had no shrinkage at the 7month follow-up and ultimately required repeat TAE. We suspect that this was due to a technical fault, such as rapid injection of microspheres leading to particle aggregation and proximal embolization. Therefore, the renal AML might not be embolized sufficiently. Hence, microspheres should be injected very slowly to prevent particle aggregation. On the other hand, rupture of the AML during TAE using PVA particles was previously reported [9]. This could be attributed to an increase in intra-tumor pressure. This complication needs to be considered even in TAE using microspheres.

On the other hand, surgery can also be a treatment option for the renal AMLs. However, it has a high risk of bleeding, particularly when the AML is large [19]. Besides, antiplatelet drug therapy can increase a risk of intraoperative bleeding [20]. Thus, it is important to reduce the intraoperative blood loss. TAE has been recently reported useful for reduction of intraoperative blood loss for complex renal tumors [21]. It may also contribute to clear surgical margins [22]. Therefore, we think TAE can be an important procedure even in surgery for the renal AML.

The present study has several limitations. The retrospective design was key limitation. Sample size was small and the follow-up period was relatively short, and thus further investigation should be needed with large sample 
size and long follow-up period. More than one operator performed the TAEs, and the procedure was not standardized due to variability in the technique according to individual operator.

\section{Conclusion}

TAE using microspheres appears to be effective and safe for unruptured sporadic renal AMLs.

\section{Abbreviations}

AML angiomyolipoma

CT computed tomography

PVA polyvinyl alcohol

TAE transcatheter arterial embolization

Funding information: No funding was obtained for this research.

Author contributions: Study conception and design: M. S. data collection and analysis: M. S., K. N., K. O., Y. S., T. N., T. N., and T. Y. interpretation: M. S., N. K. manuscript writing: M. S., Y. S. All authors read and approved the final manuscript.

Conflict of interest: The authors declare that they have no conflict of interest.

Data availability statement: The datasets generated and/ or analyzed during the current study are available from the corresponding author on reasonable request.

\section{References}

[1] Lemaitre L, Robert Y, Dubrulle F, Claudon M, Duhamel A, Danjou $P$, et al. Renal angiomyolipoma: growth followed up with CT and/or US. Radiology. 1995;197(3):598-602. doi: 10.1148/radiology.197.3.7480725.

[2] Dickinson M, Ruckle H, Beaghler M, Hadley HR. Renal angiomyolipoma: optimal treatment based on size and symptoms. Clin Nephrol. 1998;49(5):281-6.

[3] Yamakado K, Tanaka N, Nakagawa T, Kobayashi S, Yanagawa M, Takeda K. Renal angiomyolipoma: relationships between tumor size, aneurysm formation, and rupture. Radiology. 2002;225(1):78-82. doi: 10.1148/ radiol.2251011477.
[4] Andersen PE, Thorlund MG, Wennevik GE, Pedersen RL, Lund L. Interventional treatment of renal angiomyolipoma: immediate results and clinical and radiological follow-up of 4.5 years. Acta Radiol Open. 2015;4(7):2058460115592442. doi: 10.1177/ 2058460115592442.

[5] Kothary N, Soulen MC, Clark TW, Wein AJ, ShlanskyGoldberg RD, Crino PB, et al. Renal angiomyolipoma: longterm results after arterial embolization. J Vasc Interv Radiol. 2005;16(1):45-50. doi: 10.1097/01.RVI.0000143769.79774.70.

[6] Chick CM, Tan BS, Cheng C, Taneja M, Lo R, Tan YH, et al. Longterm follow-up of the treatment of renal angiomyolipomas after selective arterial embolization with alcohol. BJU Int. 2010;105(3):390-4. doi: 10.1111/j.1464-410X.2009.08813.x.

[7] Vaidya S, Tozer KR, Chen J. An overview of embolic agents. Semin Intervent Radiol. 2008;25(3):204-15. doi: 10.1055/ s-0028-1085930.

[8] Zerhouni EA, Schellhammer P, Schaefer JC, Drucker JR, Jaffe AH, Gonzales JE, et al. Management of bleeding renal angiomyolipomas by transcatheter embolization following CT diagnosis. Urol Radiol. 1984;6(3-4):205-9. doi: 10.1007/ BF02923726.

[9] Lenton J, Kessel D, Watkinson AF. Embolization of renal angiomyolipoma: immediate complications and long-term outcomes. Clin Radiol. 2008;63(8):864-70. doi: 10.1016/ j.crad.2008.02.005.

[10] Huang Q, Zhai RY. Embolization of symptomatic renal angiomyolipoma with a mixture of lipiodol and PVA, a mid-term result. Chin J Cancer Res. 2014;26(4):399-403. doi: 10.3978/ j.issn.1000-9604.2014.07.04.

[11] Laurent A. Microspheres and nonspherical particles for embolization. Tech Vasc Interv Radiol. 2007;10(4):248-56. doi: 10.1053/j.tvir.2008.03.010.

[12] Sacks D, McClenny TE, Cardella JF, Lewis CA. Society of interventional radiology clinical practice guidelines. J Vasc Interv Radiol. 2003;14(9 Pt 2):S199-202. doi: 10.1097/ 01.rvi.0000094584.83406.3e.

[13] Sildiroglu O, Saad WE, Hagspiel KD, Matsumoto AH, Turba UC. Endovascular management of iatrogenic native renal arterial pseudoaneurysms. Cardiovasc Intervent Radiol. 2012;35(6):1340-5. doi: 10.1007/s00270-011-0325-5.

[14] Han YM, Kim JK, Roh BS, Song HY, Lee JM, Lee YH, et al. Renal angiomyolipoma: selective arterial embolization-effectiveness and changes in angiomyogenic components in long-term follow-up. Radiology. 1997;204(1):65-70. doi: 10.1148/ radiology.204.1.9205224.

[15] Rimon U, Duvdevani M, Garniek A, Golan G, Bensaid P, Ramon J, et al. Ethanol and polyvinyl alcohol mixture for transcatheter embolization of renal angiomyolipoma. AJR Am J Roentgenol. 2006;187(3):762-8. doi: 10.2214/ AJR.05.0629.

[16] Sawada Y, Shimohira M, Hashizume T, Sobue R, Mori S, Nakagawa $\mathbf{M}$, et al. Transcatheter arterial embolization for renal angiomyolipoma using a micro-balloon catheter and a mixture of ethanol and lipiodol. Cardiovasc Intervent Radiol. 2017;40(12):1933-39. doi: 10.1007/s00270-017-1731-0.

[17] Hyun D, Do YS, Park KB, Kim DI, Kim YW, Park HS, et al. Ethanol embolotherapy of foot arteriovenous malformations. J Vasc Surg. 2013;58(6):1619-26. doi: 10.1016/j.jvs.2013.06.074.

[18] Soulen MC, Faykus MH Jr, Shlansky-Goldberg RD, Wein A), Cope C. Elective embolization for prevention of hemorrhage 
from renal angiomyolipomas. J Vasc Interv Radiol. 1994;5(4):587-91. doi: 10.1016/s1051-0443(94)71558-x.

[19] Kiefer RM, Stavropoulos SW. The role of interventional radiology techniques in the management of renal angiomyolipomas. Curr Urol Rep. 2017;18(5):36. doi: 10.1007/s11934017-0687-6.

[20] Voltolini L, Rapicetta C, Luzzi L, Paladini P, Ghiribelli C, Scolletta $S$, et al. Lung resection for non-small cell lung cancer after prophylactic coronary angioplasty and stenting: shortand long-term results. Minerva Chir. 2012 Feb;67(1):77-85. PMID: 22361679.
[21] Cochetti G, Zingaro MD, Boni A, Allegritti M, de Vermandois JAR, Paladini A, et al. Renal artery embolization before radical nephrectomy for complex renal tumour: which are the true advantages? Open Med (Wars). 2019 Nov 7;14:797-804. doi: 10.1515/med-2019-0095.

[22] Marulli G, Breda C, Fontana P, Ratto GB, Leoncini G, Alloisio M, et al. Pleurectomy-decortication in malignant pleural mesothelioma: are different surgical techniques associated with different outcomes? results from a multicentre study. Eur J Cardiothorac Surg. 2017 Jul 1;52(1):63-69. doi: 10.1093/ejcts/ ezx079. 